\title{
Antagonistic Roles for GcvA and GcvB in hdeAB Expression in Escherichia coli
}

\author{
Lorraine T. Stauffer and George V. Stauffer \\ Department of Microbiology, University of Iowa, Iowa City, IA 52242, USA \\ Correspondence should be addressed to George V. Stauffer, george-stauffer@uiowa.edu
}

Received 20 February 2012; Accepted 14 March 2012

Academic Editors: D. Rodriguez-Lazaro, A. Sunna, and P. Velge

Copyright ( $) 2012$ L. T. Stauffer and G. V. Stauffer. This is an open access article distributed under the Creative Commons Attribution License, which permits unrestricted use, distribution, and reproduction in any medium, provided the original work is properly cited.

\begin{abstract}
In E. coli, the periplasmic proteins $\mathrm{Hde} A$ and $\mathrm{HdeB}$ have chaperone-like functions, suppressing aggregation of periplasmic proteins under acidic conditions. A microarray analysis of RNA isolated from an E. coli wild type and a $\Delta$ gcvB strain grown to mid-log phase in Luria-Bertani broth indicated the $h d e A B$ operon, encoding the HdeA and HdeB proteins, is regulated by the sRNA GcvB. We wanted to verify that $\mathrm{GcvB}$ and its coregulator Hfq play a role in regulation of the hdeAB operon. In this study, we show that GcvB positively regulates $h d e A:: l a c Z$ and $h d e B:: l a c Z$ translational fusions in cells grown in Luria-Bertani broth and in glucose minimal media + glycine. Activation also requires the Hfq protein. Although many sRNAs dependent on Hfq regulate by an antisense mechanism, GcvB regulates $h d e A B$ either directly or indirectly at the level of transcription. GcvA, the activator of $g c v B$, negatively regulates $h d e A B$ at the level of transcription. Although expression of $g c v B$ is dependent on GcvA, activation of $h d e A B$ by GcvB occurs independently of GcvA's ability to repress the operon. Cell survival and growth at low pH are consistent with GcvA negatively regulating and GcvB positively regulating the $h d e A B$ operon.
\end{abstract}

\section{Introduction}

Acid resistance is important for the ability of enteric bacteria to survive the low $\mathrm{pH}$ environment encountered in the gastrointestinal tract of mammalian hosts and other natural environments [1]. Enteric bacteria have five systems of acid resistance [2-7]. The first system, AR1, is least understood. When cells are grown in $\mathrm{LB}$ at $\mathrm{pH} 5$ to stationary phase, they survive dilution into minimal medium at $\mathrm{pH} 2.5$, which kills cells grown at $\mathrm{pH}$. The stationary phase sigma factor RpoS and cyclic-AMP receptor protein are required to develop acid tolerance $[2,6]$. The other four systems, AR2 AR3, AR4, and AR5, are decarboxylate/antiporter-dependent acid resistance systems that require glutamate, arginine, lysine, and ornithine, respectively [2, 4-10]. Additional acid protection comes from the periplasmic proteins HdeA and HdeB that have chaperone-like functions, suppressing aggregation of periplasmic proteins under extreme acidic conditions [1113]. Both hdeA and $h d e B$ mutants show reduced viability upon acid stress and $\mathrm{HdeA} / \mathrm{HdeB}$ expressing plasmids restore viability close to wild type, suggesting both proteins are necessary for protection of the bacterial periplasm against acid stress [14]. Regulation of the hdeAB operon is complex. The hdeAB operon in $E$. coli is acid inducible and regulation involves GadE, RpoD, RpoS, H-NS, MarA, and several other regulators $[6,7,15-18]$.

The E. coli $g c v B$ gene encodes a sRNA of 206 nucleotides [19]. Expression of $g c v B$ is activated by the GcvA protein when cellular glycine is high and repressed by GcvA and GcvR when glycine is limiting [19]. In both E. coli and Salmonella enterica serovar Typhimurium, GcvB regulates genes involved in the transport of small peptides and polar and branched amino acids [19-24]. Recently, it was shown GcvB enhances the ability of E. coli to survive low $\mathrm{pH}$ by upregulating RpoS [25]. In addition, microarray data suggested the hde $A B$ operon is positively regulated by GcvB [22]. Results from this study establish a role for GcvA in repressing the hdeAB operon and GcvB in activating the operon. Hfq, an RNA chaperone required for $\mathrm{GcvB}$ regulation of known target genes [20, 22, 23, 26], is also required for activation. However, the results suggest GcvB and Hfq do not function as an antisense RNA system to upregulate hdeAB translation, 
but act at the level of transcription. The results also suggest GcvA, the activator for $g c v B$, negatively regulates $h d e A B$ at the level of transcription.

\section{Materials and Methods}

2.1. Bacterial Strains, Plasmids, and Phage. The E. coli strains, plasmids, and phage used are listed in Table 1 or described in the text.

2.2. Construction of Recombinant Phages and Plasmids. The hhdeA::lacZ translational fusion was constructed by PCR synthesis of a DNA fragment using an upstream primer with an EcoRI site that hybridized to DNA beginning 223 bps upstream of the hdeA transcription start site and a downstream primer with a SmaI site that hybridized to DNA beginning at codon 7 within the hdeA gene. The PCR amplified DNA fragment was digested with EcoRI + SmaI and the 303 bp EcoRI-SmaI fragment ligated into the EcoRI-SmaI sites of plasmid pMC1403 [37], fusing the first 7 codons of the hdeA gene in frame with the 8th codon of the lacZYA genes in pMC1403 (Figure 1(a)). The cloned sequence was verified by DNA sequence analysis at the DNA Core Facility of the University of Iowa. The plasmid was designated phdeA::lacZ. A 5,574 bp EcoRI-MfeI fragment from phdeA::lac $Z$ carrying the hdeA::lacZYA fusion was then ligated into the EcoRI site of phage $\lambda \mathrm{gt} 2$ [30], generating $\lambda$ hdeA::lacZ. A $\lambda$ hdeB::lacZ fusion was constructed using the same upstream primer and a downstream primer with a SmaI site that hybridized to DNA beginning at codon 9 within the $h d e B$ gene. The 757 bp EcoRI-SmaI fragment was then used as described above, generating plasmid phdeB::lacZ and phage $\lambda$ hdeB::lacZ (not shown). A $\lambda$ hdeA::lac $Z$ transcriptional fusion was constructed using the same upstream primer and a downstream primer with a HindIII site and that hybridized to DNA at bp -36 relative to the $h d e A$ translation start site (Figure 1(a)). Following digestion with EcoRI and HindIII, the DNA fragment was ligated into the EcoRI and HindIII sites of plasmid pgcvB-lac $Z^{+50}$ [19], replacing the $g c v B$ fragment with the hdeA fragment, generating plasmid $\mathrm{phde} A^{-36}::$ lac $Z$. The cloned sequence was verified by DNA sequence analysis. A 5,538 bp EcoRI-MfeI fragment from phde $A^{-36}::$ lac $Z$ carrying the $h d e A^{-36}::$ lac $Z Y A$ fusion was then ligated into the EcoRI site of phage $\lambda \mathrm{gt} 2$ [30], generating $\lambda$ hde $A^{-36}::$ lac $Z$. The 3 fusion phages were used to lysogenize E. coli host strains as described [38]. Each lysogen was tested to ensure it carried a single-copy of the $\lambda$ chromosome by infection with $\lambda c 190 c 17$ [39]. All lysogens were grown at $30^{\circ} \mathrm{C}$ since all fusion phage carry the $\lambda c \mathrm{I} 857$ mutation, resulting in a temperature-sensitive $\lambda c \mathrm{I}$ repressor [30]. The $\lambda \mathrm{P}_{B A D}:$ :hdeA::lac $Z$ fusion, where hdeA transcription is under control of the $\mathrm{P}_{B A D}$ promoter, was constructed as described in Figure 1(b).

Plasmid pGS611 (pgcv $\left.A^{3+}\right)$, carrying the E. coli $g c v A$ gene on a 1,155 bp EcoRI fragment, was constructed as follows. In a PCR reaction, an upstream primer was used containing an EcoRI site and that hybridized to a region beginning $121 \mathrm{bp}$ upstream of the gcvA transcription start site and a downstream primer containing an EcoRI site and hybridized to a region beginning $44 \mathrm{bp}$ downstream of the gcvA translation stop codon. The EcoRI sites were added as parts of the primers. The PCR-generated fragment was digested with EcoRI and cloned into the EcoRI site in plasmid pACYC184 [40] and verified by DNA sequence analysis (Figure 1(c)). Plasmid pGS624 (pgcvA $\left.A^{3+} g c v B^{3+}\right)$, carrying both the $g c v A$ and $g c v B$ genes, was constructed in the same way except the upstream primer hybridized to DNA 51 bps after the $g c v B$ transcription terminator and the downstream primer hybridized to DNA 44 bps after the $g c v A$ translation stop codon, generating a 1,347 bp EcoRI fragment (Figure 1(c)).

2.3. Media. The complex medium used was LB [41]. Agar was added at $1.5 \%(\mathrm{w} / \mathrm{v})$ to make solid media. The minimal medium used was the salts of Vogel and Bonner [42] supplemented with $0.4 \%(\mathrm{w} / \mathrm{v})$ glucose (GM). Ampicillin was added at 50 and $150 \mu \mathrm{g} \mathrm{mL}^{-1}$ when strains carried singlecopy and multicopy plasmids, respectively. Other supplements were added at the following concentrations $\left(\mu \mathrm{g} \mathrm{mL}^{-1}\right)$ : phenylalanine, 50; glycine, 300; thiamine, 1; TC, 10; CM, 20; X-gal, 40 .

2.4. DNA Manipulation. Plasmid DNA was isolated using a QIAprep Spin Miniprep Kit (Qiagen, Santa Clara, CA). Vent DNA polymerase and restriction enzymes were from New England Biolabs, Inc. (Beverly, MA). T4 DNA ligase was from Roche Diagnostics (Indianapolis, IN). Reactions were as described by the manufacturers.

2.5. Enzyme Assay. $\beta$-galactosidase assays were performed on mid-log phase cells $\left(\mathrm{OD}_{600} \sim 0.5\right)$ using the chloroform/SDS lysis procedure [41]. Results are the averages of two or more assays with each sample done in triplicate.

2.6. Acid Sensitivity Assay. WT, an isogenic $\triangle g c v A B$ strain and the two strains transformed with either plasmid $\mathrm{pgcv} \mathrm{B}^{2+}$ (constitutively produces $\mathrm{GcvB}$ ), $\mathrm{pgcv} \mathrm{A}^{3+}$ or $\mathrm{pgcv} \mathrm{A}^{3+} \mathrm{gcv} \mathrm{B}^{3+}$ were grown for $24 \mathrm{hr}$ at $30^{\circ} \mathrm{C}$ in $\mathrm{LB}$ and then tested for acid resistance by dilution into $\mathrm{LB}$ at $\mathrm{pH}$ 2.0. Samples of $0.2 \mathrm{~mL}$ were taken at $0,1,2$, and $4 \mathrm{hr}$ and diluted in $2 \mathrm{~mL}$ of $\mathrm{LB}$ at $\mathrm{pH}$ 7. The final $\mathrm{pH}$ of the diluted cultures was $\sim 7.0$. Cell viability was determined by plate counts. Percent survival is the titer of colony forming units of acid-tested cells compared to the zero-time point (Figure 2).

2.7. Transductions. The $g c v B$ gene is linked to the $\arg A$ gene and $h f q$ is linked to the $c y c A$ gene, with predicted phage P1 cotransduction frequencies of $\sim 78 \%$ and $\sim 67 \%$, respectively. P1clr phage prepared on GS854 (argA81::Tn10) was used to transduce $\Delta g c v B:: \Omega C M^{\mathrm{R}} \lambda$ hdeA::lacZ to $\mathrm{TC}^{\mathrm{R}}$ and transductants scored on $\mathrm{CM}$ versus TC plates. A $\mathrm{TC}^{\mathrm{R}} \mathrm{CM}^{\mathrm{S}}$ transductant was purified. P1clr prepared on GS776 (cycA::Tn10) was used to transduce $\Delta h f q-1:: \Omega \mathrm{CM}^{\mathrm{R}} \lambda$ hdeA::lac $Z$ to $\mathrm{TC}^{\mathrm{R}}$ resistance and transductants scored on $C M$ versus TC plates. A $\mathrm{TC}^{\mathrm{R}} \mathrm{CM}^{\mathrm{S}}$ transductant was purified. 
TABLE 1: Strains, plasmids, and phage.

\begin{tabular}{|c|c|c|}
\hline Strain, plasmid, or phage & Relevant genotype & Source \\
\hline \multicolumn{3}{|l|}{ Strain* } \\
\hline GS162 & WT & This lab \\
\hline GS776 & cycA30:: $\operatorname{Tn} 10$ & This lab \\
\hline GS854 & $\arg A 81:: \operatorname{Tn} 10$ & This lab \\
\hline GS998 & GS162 $g c v A$ & {$[27,28]$} \\
\hline GS1132 & GS162 $\Delta(g c v A g c v B):: \Omega a a d A$ (referred to as $\Delta g c v A B)$ & [19] \\
\hline GS1144 & GS162 $\Delta g c v B:: \Omega \mathrm{CM}^{\mathrm{R}}$ (referred to as $\left.\Delta g c v B\right)$ & {$[21]$} \\
\hline GS1148 & GS162 $h f q-1:: \Omega \mathrm{CM}^{\mathrm{R}}$ (referred to as $\left.\Delta h f q\right)$ & {$[23]$} \\
\hline \multicolumn{3}{|l|}{ Plasmid } \\
\hline pGS554 & Single-copy vector + constitutive $g c v B\left(\mathrm{pg} c v B^{2+}\right)$ & {$[19]$} \\
\hline pGS571 & Multicopy vector $+\mathrm{WT} g c v B\left(\mathrm{p} g c v B^{3+}\right)$ & {$[29]$} \\
\hline pGS594 & Single-copy vector + WT $g c v B\left(\mathrm{p} g c v B^{+}\right)$ & This lab \\
\hline pGS609 & Multi-copy vector + WT $h f q\left(\mathrm{p} h f q^{3+}\right)$ & {$[23]$} \\
\hline pGS611 & Multi-copy vector + WT $g c v A\left(p g c v A^{3+}\right)$ & This study \\
\hline pGS624 & Multi-copy vector + WT $g c v A g c v B\left(\mathrm{p} g c v A^{3+} g c v B^{3+}\right)$ & This study \\
\hline \multicolumn{3}{|l|}{ Phage } \\
\hline$\lambda \mathrm{gt} 2$ & $\lambda$ cloning vector; cI857 repressor & {$[30]$} \\
\hline$\lambda h d e A:: \operatorname{lac} Z$ & $\lambda$ vector carrying WT $h d e A:: l a c Z$ fusion & This study \\
\hline$\lambda$ hdeB::lacZ & $\lambda$ vector carrying WT $h d e B:: l a c Z$ fusion & This study \\
\hline$\lambda h d e A^{-36}:: l a c Z$ & $\lambda$ vector carrying $h d e A^{-36}:: l a c Z$ transcriptional fusion & This study \\
\hline$\lambda \mathrm{P}_{B A D}:: h d e A:: l a c Z$ & $\begin{array}{l}\lambda \text { vector carrying } h d e A:: l a c Z \text { fusion under control of the } \\
\mathrm{P}_{B A D} \text { promoter }\end{array}$ & This study \\
\hline
\end{tabular}

* All strains also carry the pheA905 thi araD129 rpsL150 relA1 deoC1 flbB5301 ptsF25 rbsR mutations.

\section{Results and Discussion}

3.1. GcvA/GcvB Role in Acid Sensitivity. Microarray data suggested the $h d e A$ and $h d e B$ mRNAs are 1.9- and 2.7-fold higher in WT than a $\triangle g c v B$ strain grown in LB, respectively [22]. These genes were not reported to be regulated by GcvB in that study because they fell below the 3-fold cut-off level used for GcvB-regulated genes. Since HdeA and HdeB are necessary for protection of the bacterial periplasm against acid stress $[14,17]$, we tested if GcvB plays a role in cellular acid resistance. WT and an isogenic $\triangle g c v A B$ strain were grown for $24 \mathrm{hr}$ at $30^{\circ} \mathrm{C}$ in $\mathrm{LB}$ and tested for acid resistance by dilution into $\mathrm{LB}$ at $\mathrm{pH} 2.0$ [43]. The WT was killed significantly more readily at $\mathrm{pH} 2$ than the $\triangle g c v A B$ strain (Figure 2, compare black and gray lines). However, when the $\triangle g c v A B$ strain was transformed with $\mathrm{pgcvB} B^{2+}$ that constitutively expresses GcvB [19], we did not see complementation that restored acid sensitivity (Figure 2, green line). When transformed with the multi-copy plasmid $\mathrm{p} g \mathrm{cv} A^{3+} g \mathrm{cv} B^{3+}$, both the WT and the $\triangle g c v A B$ transformants were more acid sensitive (Figure 2, compare the black and blue lines and the gray and purple lines). Plasmid $\mathrm{pgcv} \mathrm{A}^{3+}$, which carries only the $g \mathcal{c} v A$ gene, also complemented the $\triangle g c v A B$ mutation, increasing acid sensitivity (Figure 2, compare the gray and red lines). The results suggest it is the absence of GcvA that is responsible for increased acid resistance in the $\triangle g c v A B$ strain. It was reported previously that GcvB plays a positive role in acid resistance [25]. Our failure to observe a significant effect on acid resistance is possibly due to the assay conditions. We tested for acid resistance after 24 hours of growth in LB, whereas in the earlier study acid resistance was tested after $5 \mathrm{hr}$ of growth in LB [25]. Although the precise stage of growth was not stated in the earlier study, it is possible cells were still in log phase. In E. coli and Salmonella grown in LB, GcvB was only detected through early stationary phase, with the highest levels observed at the mid-exponential phase $[20,26]$. Thus, GcvB regulation of target genes involved in acid resistance is likely during log phase and if GcvB plays a role in stationary phase, it is its absence that is important for allowing an appropriate regulatory response.

3.2. Effects of $G c v B$ on $\lambda$ hdeA::lacZ Expression in LB Grown Cells. Although GcvB had no effect in the acid sensitivity assay, we made and tested expression of $\lambda$ hdeA::lac $Z$ and $\lambda$ hdeB::lac $Z$ translational fusions. Expression of the hdeA::lacZ fusion was 2.7- and 4-fold higher in WT grown in LB compared to $\Delta g c v B$ and $\Delta h f q$ strains (Figure 3(a), compare lanes 1, 2 and 3). Activation was partially restored in the $\Delta g c v B\left[\mathrm{pgcvB} B^{+}\right]$and $\Delta h f q\left[\mathrm{phfq^{3+ }}\right]$ complemented strains (Figure 3(a), compare lanes 2 and 4 and lanes 3 and 5). It is unknown why the plasmids fail to fully complement the $\Delta g c v B$ and $\Delta h f q$ mutations. Nevertheless, the results agree with microarray data and suggest GcvB and Hfq positively regulate hdeA::lac $Z$. 


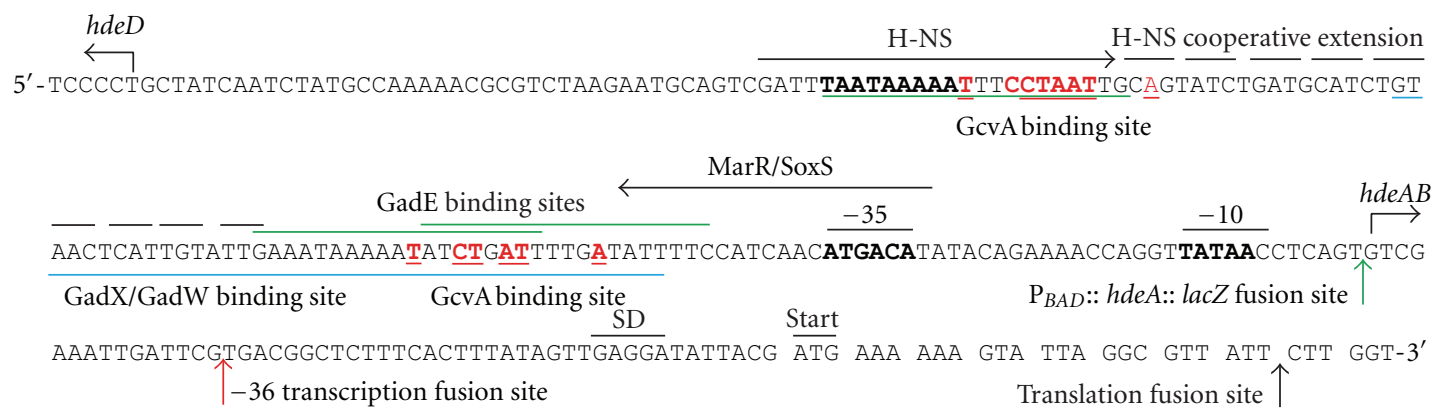

(a)

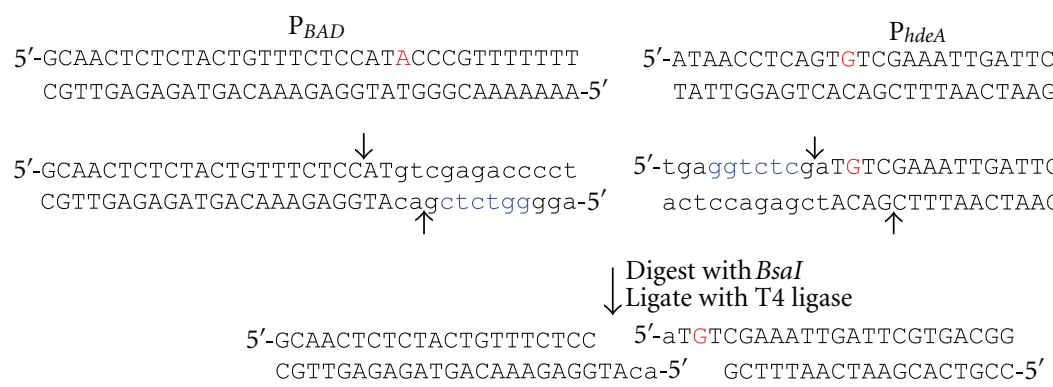

(b)

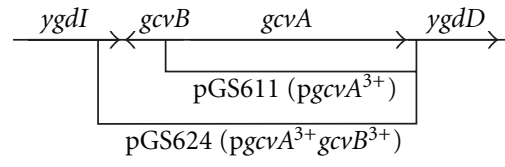

(c)

Figure 1: (a) The $h d e A B$ control region. The $h d e A B$ promoter $-35,-10$ and transcription start site and the SD sequence and translation start site are indicated above the sequence [31]. The transcription start site for the divergently transcribed hdeD gene is also shown [32]. Binding sites for H-NS [16] and MarR/SoxS [15] are indicated above the sequence with arrows. The binding site for GadX/W [33] is below the sequence in blue and for GadE above the sequence in green $[18,34]$. In addition, there are putative binding sites for the transcriptional regulators Lrp and TorR (not shown) [34]. The consensus GcvA binding site is T-N ${ }_{11}$-A containing a $5^{\prime}$-CTAAT-3' sequence [35]. Two putative GcvA binding sites are indicated in red. The fusion sites for the $\lambda h d e A::$ lac $Z$ translational fusion, the $\lambda h d e A^{-36}::$ lac $Z$ transcriptional fusion, and the $\lambda \mathrm{P}_{B A D}:: h d e A::$ lac $Z$ fusion (see below) are indicated with black, red, and green arrows, respectively. (b) Construction of a $\lambda \mathrm{P}_{B A D}::$ hdeA::lacZ promoter fusion. The $\mathrm{WT} \mathrm{P}_{B A D}$ and $\mathrm{P}_{h d e A}$ promoters are shown in the top line. The transcription start sites are in red $[31,36]$. Small case letters show bases added during PCR amplification of the $\mathrm{P}_{B A D}$ and $\mathrm{P}_{\text {hdeA }}$ promoters. The $\mathrm{P}_{B A D}$ promoter was amplified with an upstream primer containing an EcoRI site at bp -272 relative to the transcription start site (not shown) and a downstream primer with a $B s a \mathrm{I}$ site (blue). The $\mathrm{P}_{h d e A}$ promoter was amplified with an upstream primer containing a BsaI site (blue) and a downstream primer containing a SmaI site at codon 10 in the hdeA gene (not shown). The arrows indicate cut sites for BsaI. The amplified products were cut with $B s a \mathrm{I}$, mixed, and ligated, generating a fusion of the $\mathrm{P}_{B A D}$ promoter with the $+1 \mathrm{G}$ residue of the $\mathrm{P}_{\text {hdeA }}$ promoter. The fragment was then digested with EcoRI $+S m a I$ and ligated into the EcoRI-SmaI sites of plasmid pMC1403, and subsequently subcloned into $\lambda$ gt 2 as described [19]. (c) The $g c v A g c v B$ region of the E. coli chromosome. The regions amplified by PCR and cloned into pACYC184 to generate pGS611 $\left(\mathrm{p} g c v A^{3+}\right)$ and pGS624 $\left(\mathrm{pgcv} A^{3+} g c v B^{3+}\right)$ are indicated with bars. See Section 2.2 for details.

3.3. Reduced hdeA::lacZ Expression in $\Delta g c v B$ and $\Delta h f q$ Strains Is due to the Absence of $G c v B$ and $H f q$. Due to the failure of $\mathrm{pgcvB} B^{+}$and $\mathrm{phfq} \mathrm{q}^{3+}$ to fully complement the $g c v B$ and $h f q$ mutations (Figure 3 ), we wanted to verify the reduced levels of $h$ deA-lac $Z$ expression are due to the absence of GcvB and Hfq. We transduced the $\Delta g c v B$ and $\Delta h f q$ lysogens with WT alleles using linked Tn10 markers. The $g c v B^{+}$ and $h \mathrm{fq}^{+}$transductants showed about the same levels of expression as the WT lysogen (Figure 3(a), compare lanes 1, 12 and 13). Thus, despite the failure of $\mathrm{pgcvB} B^{+}$and $\mathrm{phfq} \mathrm{q}^{3+}$ to fully complement, the results support the reduced levels of expression are due to the absence of GcvB and Hfq.

3.4. Effects of GcvA on $\lambda$ hdeA::lacZ Expression in LB Grown Cells. The acid sensitivity assay showed GcvA plays a role in acid resistance (Figure 2). In addition, putative GcvA binding sites can be identified in the hdeA promoter region (Figure 1(a)). Thus, we tested the effects of a spontaneous
gcvA mutation in strain GS1198 (which is phenotypically $\left.\mathrm{GcvB}^{-}[19]\right)$, on hdeA::lacZ expression. Expression of hdeA::lacZ was $\sim 1.5$-fold higher in WT than in the gcvA mutant (Figure 3, lanes 1 and 6). However, expression was 2-fold higher in the $g c v A$ lysogen than in the $\Delta g c v B$ lysogen (Figure 3(a), compare lanes 2 and 6). The results could be explained if GcvA, in addition to activating expression of $g c v B$, which encodes a positive regulator for $h d e A$, also has a negative role to keep HdeAB levels low. The intermediate level of expression would result from the absence of GcvB to upregulate the hdeA::lacZ fusion and the absence of GcvA to negatively regulate the fusion. To test this hypothesis, we transformed the $g c v A$ mutant with multi-copy $\mathrm{p} g c v A^{3+}$. In the $g c v A\left[\mathrm{p} g c v A^{3+}\right]$ lysogen, one would expect high GcvA levels, but GcvB would also be produced. Expression of hdeA::lacZ was 2.5-fold higher in WT than in the $g c v A\left[\mathrm{pgcv} A^{3+}\right]$ transformant (Figure 3(a), compare lanes 1 and 8$)$. In addition, $h d e A:$ :lac $Z$ expression was reduced 2 -fold 


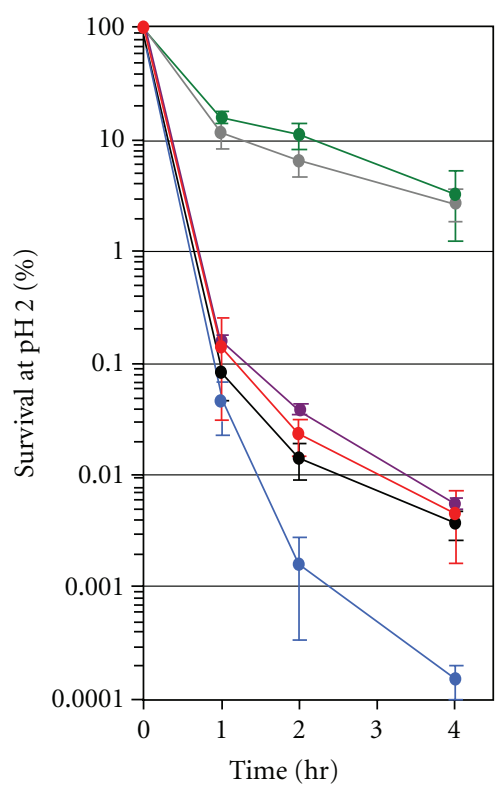

Figure 2: Percent survival of E. coli strains plotted against time at $\mathrm{pH}$ 2.0. Black, WT; gray, $\triangle g c v A B$; green, $\Delta g c v A B\left[\mathrm{pgcv} B^{2+}\right]$; blue, WT[p $\left.g c v A^{3+} g c v B^{3+}\right]$; purple, $\Delta g c v A B\left[\mathrm{p} g c v A^{3+} g c v B^{3+}\right]$; red, $\triangle g c v A B\left[\mathrm{pgcv} A^{3+}\right]$. See Section 2.6 for details.

compared to the nontransformed $g c v A$ strain (Figure 3(a), lanes 6 and 8). We then transformed the $\triangle g c v A B$ lysogen with $\mathrm{p} g c v A^{3+}$. In the $\triangle g c v A B\left[\mathrm{p} g c v A^{3+}\right]$ lysogen, there would be high GcvA levels and no GcvB, and repression of hdeA::lacZ should be greatest. In the $\triangle g c v A B\left[\mathrm{pgcv} A^{3+}\right]$ lysogen there was a 5.8 -fold reduction of hdeA-lac $Z$ expression compared to WT and a 2.4-fold reduction compared to the $\triangle g c v A B$ lysogen (Figure 3(a), compare lanes 1, 7 and 9). The results support a role for GcvA in negatively regulating hdeA::lac $Z$ expression.

3.5. GcvB Positively Regulates hdeA:::lacZ Independent of GcvA. If GcvA plays a negative role in hdeA::lac $Z$ expression, GcvB could function to prevent the GcvA effect. Alternatively, GcvB could function independent of GcvA to activate hdeA::lacZ. To test these two possibilities, we transformed the $\Delta g c v A B \lambda h d e A:: l a c Z$ lysogen with $\operatorname{pgcv} B^{2+}$, which makes GcvB constitutively [19]. If GcvB's role is to block GcvA's ability to repress hdeA::lacZ expression, we hypothesized there would be no effect of $G c v B$ in a $\triangle g c v A B \lambda h d e A::$ lacZ lysogen without GcvA. Alternatively, if $\mathrm{GcvB}$ positively regulates $h d e A:: l a c Z$, we hypothesized expression of $g c v B$ would increase $h d e A:: l a c Z$ expression. In the $\triangle g c v A B\left[\mathrm{pgcv} B^{2+}\right]$ lysogen, $h d e A:$ :lac $Z$ expression increased 1.7-fold compared to the non-transformed lysogen, almost to the WT level (Figure 3(a), compare lanes 1, 7 and 10). We also transformed the $\triangle g c v A B \lambda h d e A$ ::lac $Z$ lysogen with $\mathrm{p} g c v A^{3+} g c v B^{3+}$, which overproduces both GcvA and GcvB. Repression of $h d e A$ ::lac $Z$ was restored, but not as low as in the $\mathrm{p} g c v A^{3+}$ transformant (Figure 3(a), compare lanes 9 and 11). It is likely that the high GcvB levels partially negate the effect of high GcvA levels. The results suggest GcvB plays a role in activating $h d e A:: l a c Z$ independent of GcvA.

3.6. Effect of GcvA, GcvB, and $H f q$ on hdeA:::lacZ Expression in $G M+$ Glycine. In E. coli, GcvB represses $d p p A::$ lacZ, oppA::phoA, cycA::lacZ, and sstT::lacZ fusions when cells are grown in LB, but does not significantly repress these fusions when grown in GM + glycine [19, 22, 23]. However, $g c v B$ is differentially regulated over a 25 -fold range in GM supplemented with inosine versus glycine [19]. We hypothesize some genes respond to GcvB levels in GM media. Microarray data suggested the hdeA mRNA is 1.6fold higher in WT than a $\triangle g c v B$ strain grown in GM + glycine [22]. In GM + glycine, hdeA::lacZ expression was significantly higher than for cells grown in LB (Figure 3, compare $\mathrm{a}$ and $\mathrm{b}$ ). In addition, although there are small differences in fold regulation for individual strains, there was a similar regulatory pattern in GM + glycine as observed in LB. The results suggest GcvB positively regulates $h d e A$ in $\mathrm{LB}$ and $\mathrm{GM}+$ glycine. The results are important since they confirm GcvB does regulate in GM + glycine. In addition, acid resistance mechanisms are most active in the stationary phase in rich media $[6,7,44,45]$. Our results suggest GcvA and GcvB could play important roles in acid resistance during the log phase of growth in both rich and minimal medium.

3.7. Effect of $G c v A, G c v B$, and $H f q$ on hdeB::lacZ Expression. The $h d e B$ gene is the second gene in the $h d e A B$ operon. We tested if $h d e B$ is regulated in a manner similar to the $h d e A$ gene. There were small differences in the levels of $h d e B:: l a c Z$ expression in response to $\mathrm{GcvB}, \mathrm{GcvA}$, and $\mathrm{Hfq}$ compared to hdeA::lacZ in both LB and GM + glycine (compare Figures 3(a) and 3(b) with Figures 3(c) and 3(d)). Qualitatively, however, the $\lambda h d e B::$ lac $Z$ fusion showed essentially an identical pattern of expression compared to the hdeA::lac $Z$ fusion, suggesting both genes of the operon are regulated in a similar manner by GcvA, GcvB, and Hfq.

It is worth noting that $\Delta h f q$ lysogens consistently showed lower levels of hdeA::lac $Z$ and $h d e B:: l a c Z$ expression than $\Delta g c v B$ lysogens in both LB and GM + glycine (Figure 3). Two other sRNAs, DsrA, and GadY, are known to play roles in regulation of acid-resistance genes [46, 47]. Since both sRNAs require $\mathrm{Hfq}$, it is not surprising the absence of $\mathrm{Hfq}$ has a more dramatic effect on $h d e A B$ expression than the absence of GcvB.

3.8. High Levels of GcvA, GcvB, and $H f q$ in WT Alters hdeA::lacZ and hdeB::lacZ Expression. To verify GcvA negatively regulates and $\mathrm{GcvB}$ and $\mathrm{Hfq}$ positively regulate the $h d e A B$ operon, we transformed WT $\lambda h d e A:: l a c Z$, and WT $\lambda h d e B::$ lac $Z$ lysogens with plasmids carrying $g c v A, g c v B$, both $g c v A+g c v B$, or $h f q$. We hypothesized high GcvB and Hfq would increase expression and high GcvA would repress expression. The lysogens were grown in LB and assayed for $\beta$-galactosidase. The presence of $\mathrm{p} g c v B^{3+}$ resulted in a small increase in hdeA::lac $Z$ expression and about a 2 -fold increase in $h d e B:: l a c Z$ (Figures 4(a) and 4(b), lines 1 and 2). 


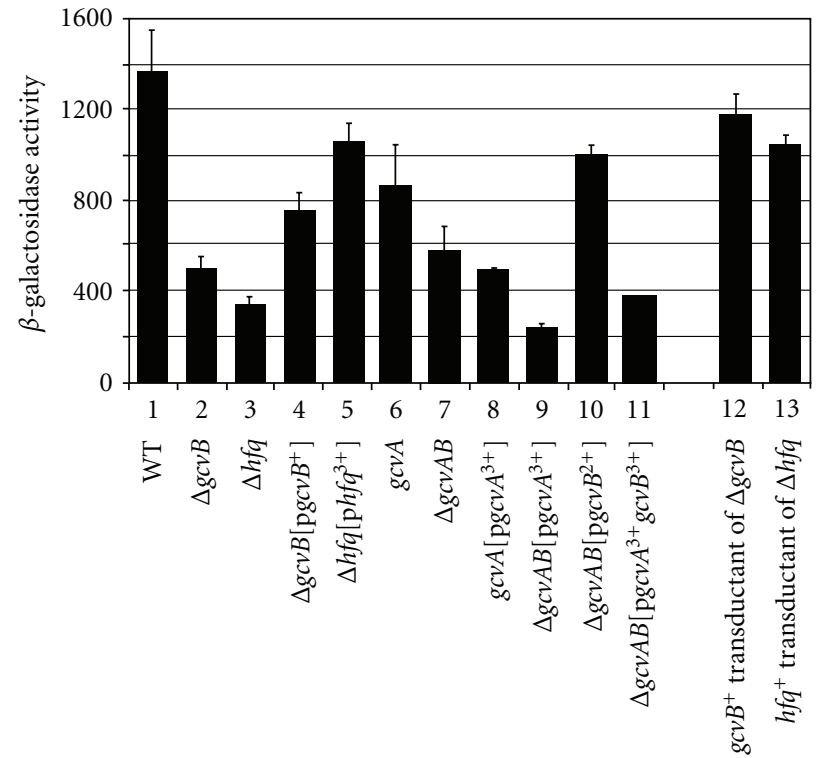

(a)

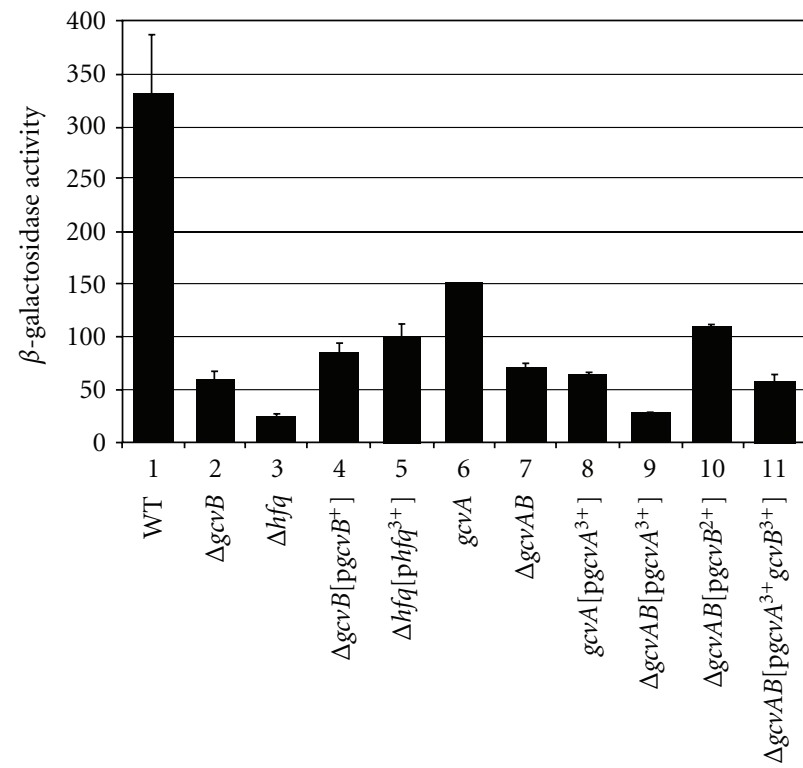

(c)

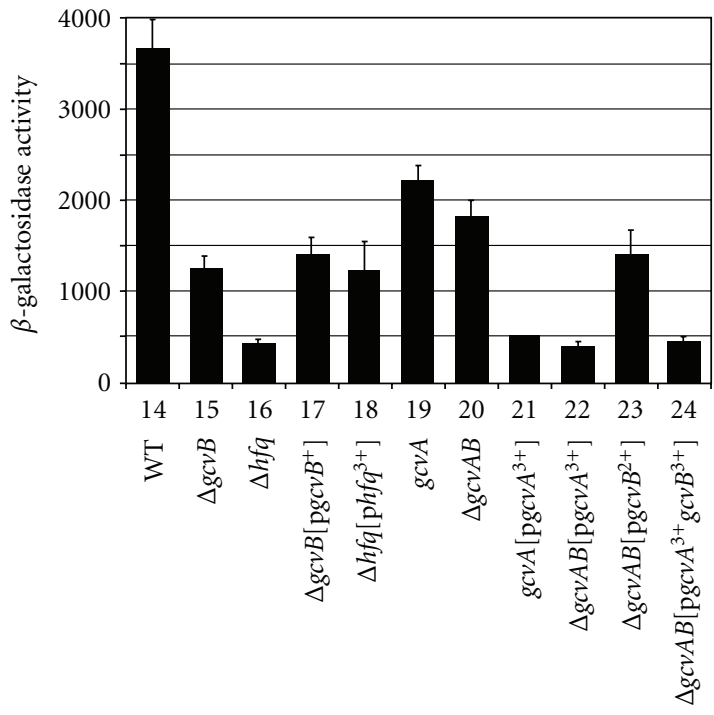

(b)

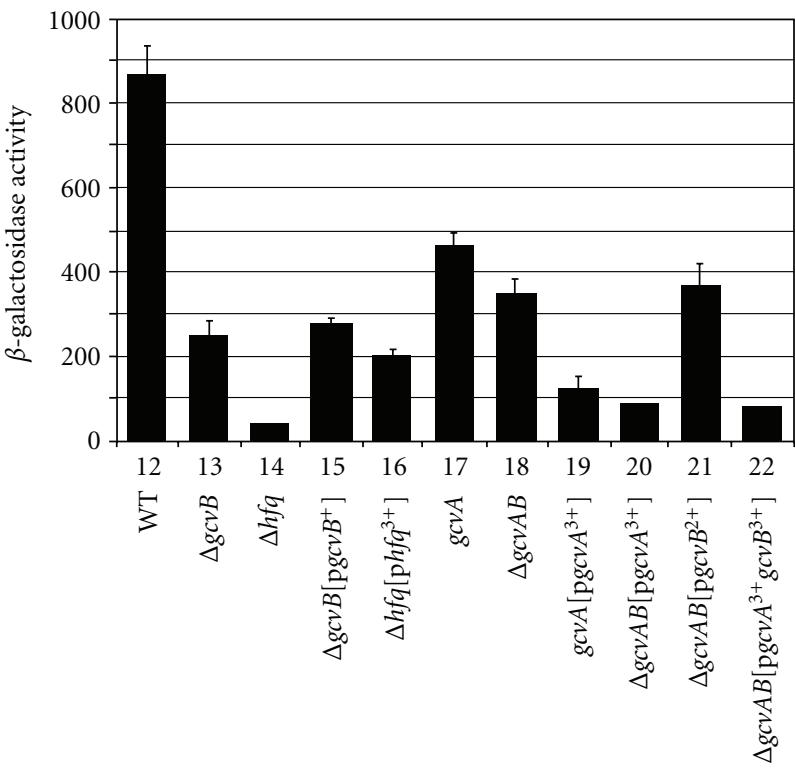

(d)

Figure 3: Effect of GcvB, Hfq, and GcvA on $\lambda$ hdeA::lacZ and $\lambda$ hdeB::lacZ expression. $\lambda$ hdeA::lacZ lysogens were grown in (a) LB or (b) GM + glycine to mid-log phase and assayed for $\beta$-galactosidase activity. $\lambda$ hdeB::lac $Z$ lysogens were grown in (c) LB or (d) GM + glycine to mid-log phase and assayed for $\beta$-galactosidase activity.

The presence of $\mathrm{phfq}^{3+}$ resulted in a 2 -fold increase in both $h d e A:: l a c Z$ and $h d e B::$ lac $Z$ expression (Figures $4(\mathrm{a})$ and 4(b), line 3). The presence of $\mathrm{pgcvA} A^{3+}$ resulted in a 3.5fold and a 2.2-fold reduction in hdeA::lac $Z$ and $h d e B:: l a c Z$ expression, respectively (Figures $4(\mathrm{a})$ and $4(\mathrm{~b})$, line 4$)$. The presence of plasmid $\mathrm{pgcv} A^{3+} g c v B^{3+}$ reduced $h d e A:: l a c Z$ and hdeB::lac $Z$ expression, but not to the levels of the $\operatorname{pgcv} A^{3+}$ plasmid (Figures 4(a) and 4(b), line 5), suggesting high GcvB antagonize the GcvA effect.

The lysogens were also grown in GM + glycine. The pattern of regulation was similar to the LB grown lysogens with one exception. The $\mathrm{p} g c v B^{3+}$ transformant did not show increased expression of $h d e B:: l a c Z$ as in LB (Figure 4(b), compare lines 1 and 2 with lines 6 and 7). It is possible that in WT grown in GM + glycine GcvB is already in excess for regulation. Nevertheless, the results are in agreement with GcvB and Hfq positively regulating the $h d e A B$ operon and GcvA negatively regulating the operon.

3.9. GcvA, GcvB, and Hfq Regulate hdeA::lacZ at the Level of Transcription. GcvA binds DNA and functions to either activate or repress transcription $[27,35,48]$, whereas sRNAs that require Hfq usually regulate posttranscriptionally [19, 2123]. To determine at what step in regulation of hdeA GcvA, 


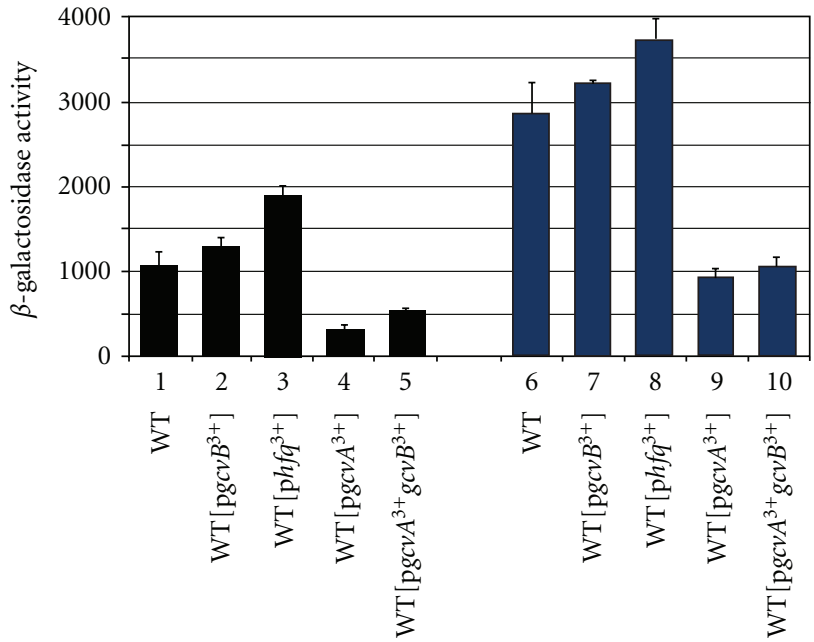

(a)

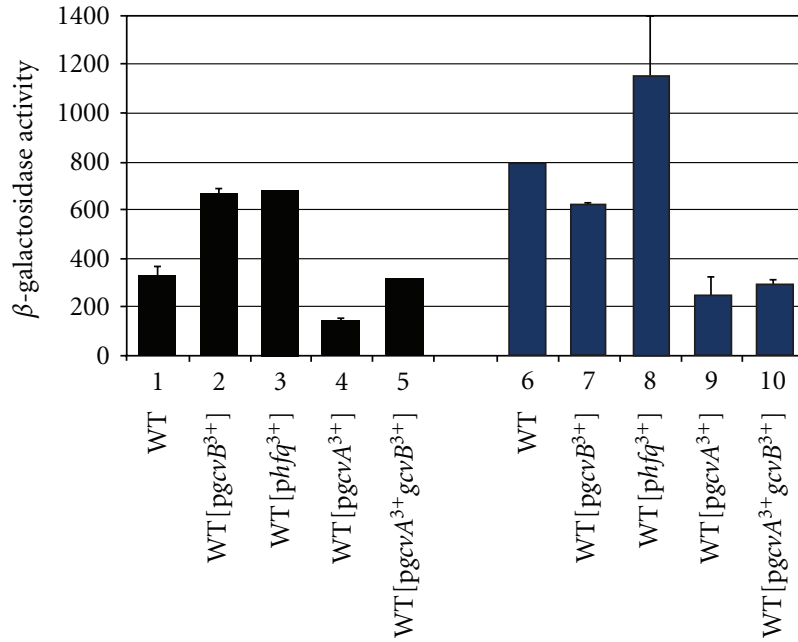

(b)

FIgure 4: WT $\lambda h d e A:: l a c Z$ and WT $\lambda h d e B:: l a c Z$ lysogens with the indicated plasmids were grown in LB (black) or GM + glycine (blue) to mid-log phase and assayed for $\beta$-galactosidase activity.

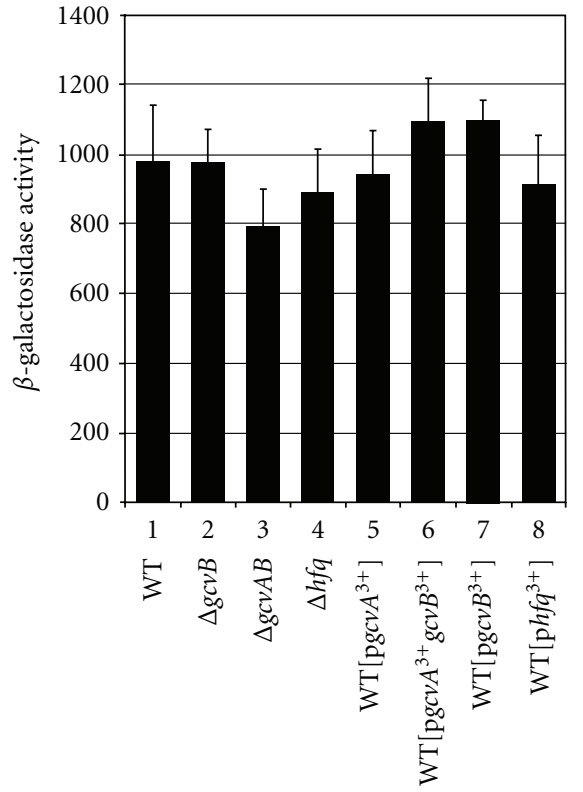

(a)

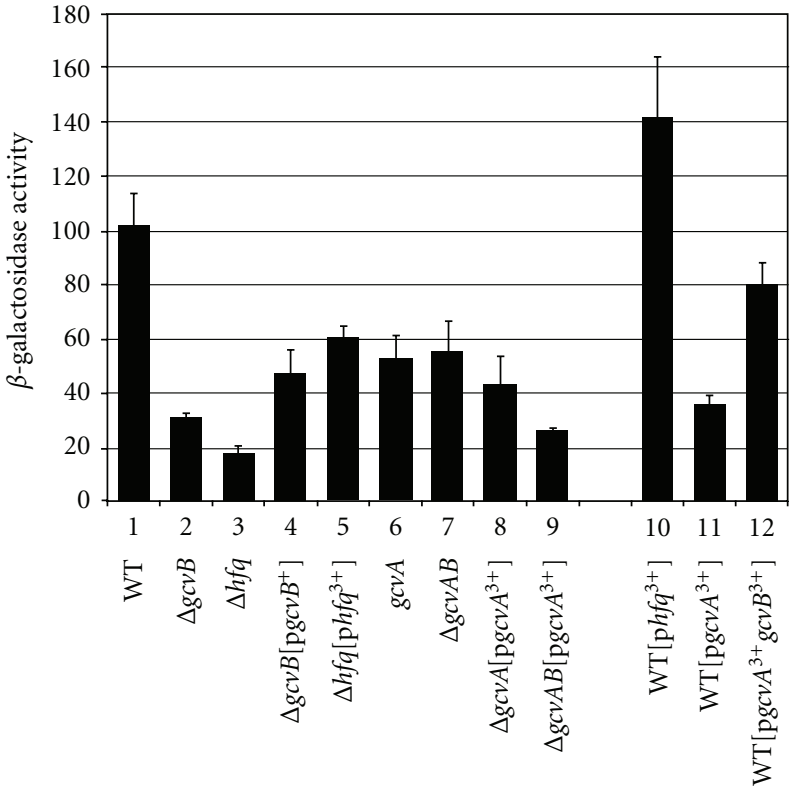

(b)

Figure 5: (a) $\mathrm{P}_{B A D}:$ :hdeA::lacZ and (b) hdeA $A^{-36}:$ :lacZ lysogens were grown in LB to mid-log phase and assayed for $\beta$-galactosidase activity.

GcvB and Hfq function, we constructed a $\lambda \mathrm{P}_{B A D}:$ :hdeA::lac $Z$ fusion where transcription from the $\mathrm{P}_{B A D}$ promoter begins at the +1 start site of the hdeA gene (Figure 1(b)). We initially lysogenized a WT strain with the fusion, the lysogen was grown in LB + arabinose ( 0.0 to $0.2 \%$ concentrations) and assayed for $\beta$-galactosidase. There was a 379 -fold induction (2.3 units versus 872 units of activity) at $0.0 \%$ and $0.05 \%$ arabinose, respectively. This is similar to the level observed from the $\lambda$ hdeA::lac $Z$ lysogen grown in LB (Figure 3) and confirmed the fusion is inducible by arabinose. We then lysogenized WT, $\Delta g c v B, \Delta g c v A B$, and $\Delta h f q$ strains. The WT lysogen was also transformed with the plasmids indicated in Figure 5(a). The strains were grown in LB $+0.05 \%$ arabinose and assayed for $\beta$-galactosidase. If GcvA, GcvB, and Hfq regulate at the transcriptional level, we expected they would no longer have an effect on the $\mathrm{P}_{B A D}$ ::hdeA::lac $Z$ fusion. Alternatively, if any of the factors regulates posttranscriptionally, we expected it would still regulate the fusion, as the mRNA is identical to the WTגhdeA::lacZ mRNA transcript. There was no significant difference in $\mathrm{P}_{B A D}:: h d e A:: l a c Z$ expression in the WT, WT[p $\left.g c v A^{3+}\right]$ and WT[p $\left.g c v A^{3+} g c v B^{3+}\right]$ transformants (Figure 5(a), compare 


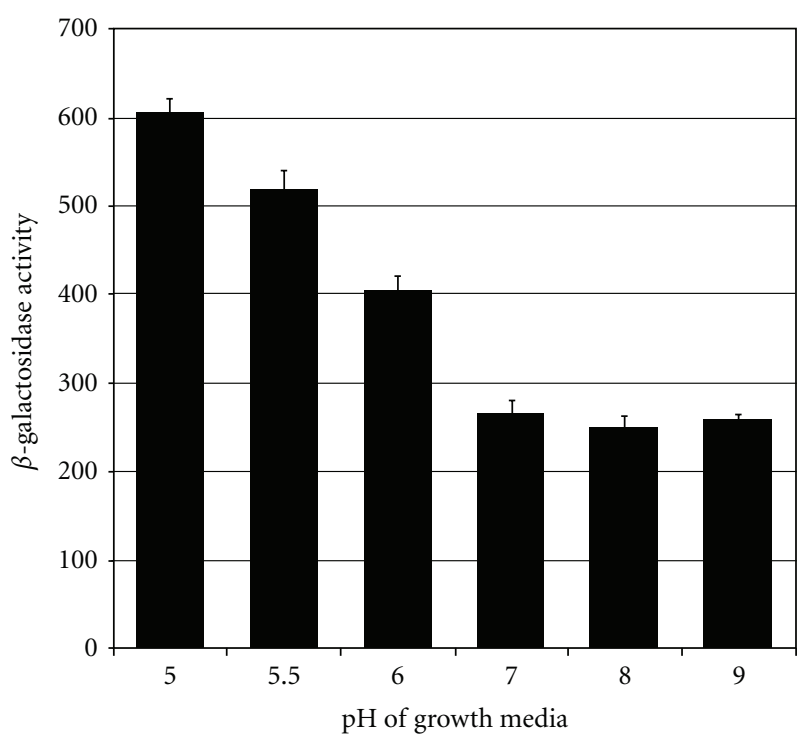

Figure 6: A WT $\lambda g c v B::$ lacZ lysogen was grown in LB buffered at different $\mathrm{pH}$ values to mid-log phase of growth and assayed for $\beta$ galactosidase activity.

lane 1 with lanes 5 and 6). The results show GcvA regulates $h d e A B$ at the level of transcription. Furthermore, there was no significant difference between WT and the $\Delta g c v B$, $\triangle g c v A B$, and $\Delta h f q$ lysogens and the WT[p $\left.g c v B^{3+}\right]$ and

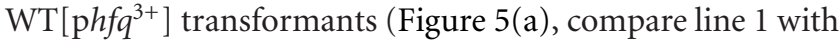
2, 3, 4, 7 and 8). The results show GcvB and Hfq also regulate at the level of transcription.

As a complement to the above experiment, we constructed a transcriptional fusion of the $h d e A$ promoter $36 \mathrm{bps}$ upstream of the hdeA translation start site to a promoterless lacZYA operon (Figure 1(a)). Expression of $h d e A^{-36}:: l a c Z$ was 3.3- and 5.6-fold higher in WT grown in LB compared to $\Delta g c v B$ and $\Delta h f q$ strains (Figure 5(b), lanes $1-3)$ and activation was partially restored in the $\Delta g c v B\left[\mathrm{p} g c v B^{+}\right]$and $\Delta h f q\left[\mathrm{phfq^{3+ }}\right]$ complemented strains (Figure 5(b), compare lanes 2 and 4 and 3 and 5). The results show GcvB and Hfa still regulate the fusion. Expression in the WT was $\sim 2$-fold higher than in the $\triangle g c v A$ and $\triangle g c v A B$ lysogens (Figure 5(b), lanes 1, 6 and 7). In the $\triangle g c v A\left[\mathrm{pgcv} A^{3+}\right]$ and $\triangle g c v A B\left[\mathrm{p} g c v A^{3+}\right]$ lysogens, there was a 2.4- and 3.9-fold reduction of $h d e A^{-36}::$ lac $Z$ expression compared to WT (Figure 5(b), compare lanes 1, 8 and 9), showing GcvA negatively regulates the fusion. We also transformed the WT lysogen with plasmids $\mathrm{p} h f q^{3+}, \mathrm{p} g c v A^{3+}$, and $\mathrm{p} g c v \mathrm{~A}^{3+} \mathrm{gcv} B^{3+}$. The presence of $\mathrm{phfq} q^{3+}$ resulted in a 1.4-fold increase in expression (Figure 5(b), lanes 1 and 10), showing Hfq does positively regulate the fusion. The presence of plasmid $\mathrm{pgcvA}{ }^{3+}$ resulted in a 2.7-fold decrease in expression (Figure 5(b), lanes 1 and 11), consistent with GcvA negatively regulating the fusion. The presence of $\mathrm{p} g c v \mathrm{~A}^{3+} g c v B^{3+}$ reduced expression 1.3-fold (Figure 5(b), lanes 1 and 12), suggesting GcvB partially overcome the GcvA effect. The results are consistent with GcvA negatively regulating $h d e A B$ at the transcriptional level. Our results also show GcvB and Hfq function during log phase to positively regulate $h d e A B$ at the transcriptional level, counterbalancing the negative effect of GcvA on downregulating these genes. GcvB is known to bind Hfq [49]. It is possible GcvB binds to and sequesters Hfa during exponential growth, and the effects observed are due to decreased levels of Hfq to alter regulation of genes such as rpoS or the activity of sRNAs such as DsrA and GadY that play roles in acid resistance. Additional studies will verify if GcvA directly binds the $h d e A B$ promoter region and how GcvB and Hfq activate the operon.

3.10. Effect of $p H$ on $g c v B$ Expression. Our results suggest GcvB plays a role in acid resistance during log phase of growth in rich and minimal media. Therefore, we tested if $\mathrm{pH}$ plays a role in regulating $g c v B$ expression. A WT $\lambda g c v B:: l a c Z$ fusion was grown to mid-log phase in $\mathrm{LB}$ at different $\mathrm{pH}$ values from 5.0 to 9.0 and assayed for $\beta$-galactosidase. There was no significant effect from $\mathrm{pH} 7$ to $\mathrm{pH} 9$ on $g c v B:: l a c Z$ expression (Figure 6). However, there was a 3 -fold increase as the $\mathrm{pH}$ was lowered from $\mathrm{pH} 7$ to $\mathrm{pH} 5$ (Figure 6). Since GcvB activates $h d e A B$, an increase in $g c v B$ expression at low $\mathrm{pH}$ is likely to play a role in final HdeAB levels and in controlling acid resistance.

\subsection{Effect of GcvA and GcvB on Cell Growth at Low pH.} We carried out studies to show the effects of high GcvA and GcvB levels on growth at low $\mathrm{pH}$. In a $\triangle g c v A B$ strain transformation with $\mathrm{p} g c v A^{3+}$ or $\mathrm{p} g c v A^{3+} g c v B^{3+}$ did not significantly alter generation times (GTs) in $\mathrm{LB}$ at $\mathrm{pH} 7$ (Table 2). At pH 4.5, GTs of both the WT and $\Delta g c v B$ strains were significantly increased (Table 2, compare rows 1 and 2 , pH 7.0 versus $\mathrm{pH} 4.5)$. In addition, in the WT[p $\left.g c v A^{3+}\right]$ strain, with high GcvA and low GcvB, there was a significant increase in the GT compared to the non-transformed WT strain (Table 2, compare rows 1 and $3, \mathrm{pH} 4.5$ ). In the $g c v A B\left[p g c v A^{3+}\right]$ transformant, with high GcvA and no GcvB, there was an additional increase in the GT (Table 2, compare rows 3 and 4, pH 4.5 column). In the WT[p $\left.g c v A^{3+} g c v B^{3+}\right]$ and $\Delta g c v A B\left[p g c v A^{3+} g c v B^{3+}\right]$ strains, with high GcvA and GcvB, the GTs were not significantly different than in the non-transformed strains (Table 2, compare rows 1 and 2 with rows 5 and $6, \mathrm{pH} 4.5)$. The results are consistent with GcvA negatively regulating acid resistance genes and GcvB overcoming the negative effect of GcvA. The results also show GcvA and GcvB affect acid resistance in log phase cells and could play important roles in the ability of enteric organisms to colonize the GI tract.

3.12. Role of GcvB in Cell Physiology. In E. coli, GcvB negatively regulates $S s t T, C y c A, O p p A$, and DppA levels, the serine transporter, glycine transporter and the oligopeptide, and dipeptide periplasmic binding proteins, respectively [19, $22,23]$. These proteins not only transport amino acids and peptides to provide nutrients, but possibly toxins and antibiotics $[50,51]$. If conditions that favor relatively high levels of amino acids and small peptides also favor the presence of small toxic compounds, the decreased expression 
TABLE 2: Effect of GcvA and GcvB on growth at low pH.

\begin{tabular}{|c|c|c|}
\hline \multirow{2}{*}{ Strain } & \multicolumn{2}{|c|}{ GT (min) grown in LB at } \\
\hline & $\mathrm{pH} 7.0$ & $\mathrm{pH} 4.5^{*}$ \\
\hline (1) WT & $52 \pm 5$ & $133 \pm 2$ \\
\hline (2) $\triangle g c v A B$ & $56 \pm 2$ & $160 \pm 6$ \\
\hline (3) $\mathrm{WT}\left[\mathrm{pg} c v A^{3+}\right]$ & $67 \pm 7$ & $306 \pm 9$ \\
\hline (4) $\triangle g c v A B\left[\mathrm{p} g c v A^{3+}\right]$ & $60 \pm 6$ & $437 \pm 45$ \\
\hline (5) WT[pgcv $\left.A^{3+} g c v B^{3+}\right]$ & $67 \pm 7$ & $157 \pm 4$ \\
\hline (6) $\Delta g c v A B\left[\mathrm{p} g c v A^{3+} g c v B^{3+}\right]$ & $62 \pm 1$ & $150 \pm 5$ \\
\hline
\end{tabular}

${ }^{*}$ Cultures were tested at the end of the experiment to verify the $\mathrm{pH}$ had not changed.

of transport systems for these small molecules by $\mathrm{GcvB}$ could prevent transport of toxic compounds into the cell [22]. Our results show that GcvB also positively regulates genes involved in acid resistance. In addition, GcvA, the activator for $g c v B$ expression, negatively regulates genes involved in acid resistance. These findings suggest GcvB and GcvA play important roles in the ability of E. coli to survive low $\mathrm{pH}$ conditions. Recently, in a screen of a sRNA gene knockout library, GcvB was shown to enhance E. coli survival at low $\mathrm{pH}$ [25]. Thus, GcvB likely allows E. coli to respond to and survive two stress conditions, the presence of toxic compounds and low $\mathrm{pH}$ environments. Both of these conditions are encountered as E. coli moves from an external environment into the GI tract. Understanding the biological roles of GcvB and GcvA in acid resistance and their mechanism(s) of regulation will provide insights as to how cells respond to environmental challenges to infect host organisms.

\section{Acknowledgments}

This work was supported by Public Health Service Grant GM069506 from the National Institute of General Medical Sciences and the Vice President for Research, the Carver College of Medicine and the Department of Microbiology, University of Iowa.

\section{References}

[1] D. S. Merrell and A. Camilli, "Acid tolerance of gastrointestinal pathogens," Current Opinion in Microbiology, vol. 5, no. 1, pp. 51-55, 2002.

[2] M. P. Castanie-Cornet, T. A. Penfound, D. Smith, J. F. Elliott, and J. W. Foster, "Control of acid resistance in Escherichia coli," Journal of Bacteriology, vol. 181, no. 11, pp. 3525-3535, 1999.

[3] B. M. Hersh, F. T. Farooq, D. N. Barstad, D. L. Blankenhorn, and J. L. Slonczewski, "A glutamate-dependent acid resistance gene in Escherichia coli," Journal of Bacteriology, vol. 178, no. 13, pp. 3978-3981, 1996.

[4] J. Lin, In Soo Lee, J. Frey, J. L. Slonczewski, and J. W. Foster, "Comparative analysis of extreme acid survival in Salmonella typhimurium, Shigella flexneri, and Escherichia coli," Journal of Bacteriology, vol. 177, no. 14, pp. 4097-4104, 1995.

[5] P. L. Moreau, "The lysine decarboxylase CadA protects Escherichia coli starved of phosphate against fermentation acids," Journal of Bacteriology, vol. 189, no. 6, pp. 2249-2261, 2007.

[6] J. W. Foster, "Escherichia coli acid resistance: tales of an amateur acidophile," Nature Reviews Microbiology, vol. 2, no. 11, pp. 898-907, 2004.

[7] B. Zhao and W. A. Houry, "Acid stress response in enteropathogenic gammaproteobacteria: an aptitude for survival," Biochemistry and Cell Biology, vol. 88, no. 2, pp. 301-314, 2010.

[8] J. P. Audia, C. C. Webb, and J. W. Foster, "Breaking through the acid barrier: an orchestrated response to proton stress by enteric bacteria," International Journal of Medical Microbiology, vol. 291, no. 2, pp. 97-106, 2001.

[9] S. Gong, H. Richard, and J. W. Foster, "YjdE (AdiC) is the arginine:Agmatine antiporter essential for arginine-dependent acid resistance in Escherichia coli," Journal of Bacteriology, vol. 185, no. 15, pp. 4402-4409, 2003.

[10] R. Iyer, C. Williams, and C. Miller, "Arginine-agmatine antiporter in extreme acid resistance in Escherichia coli," Journal of Bacteriology, vol. 185, no. 22, pp. 6556-6561, 2003.

[11] K. S. Gajiwala and S. K. Burley, "HDEA, a periplasmic protein that supports acid resistance in pathogenic enteric bacteria," Journal of Molecular Biology, vol. 295, no. 3, pp. 605-612, 2000.

[12] D. S. Merrell, D. L. Hava, and A. Camilli, "Identification of novel factors involved in colonization and acid tolerance of Vibrio cholerae," Molecular Microbiology, vol. 43, no. 6, pp. 1471-1491, 2002.

[13] W. Hong, W. Jiao, J. Hu et al., "Periplasmic protein HdeA exhibits chaperone-like activity exclusively within stomach $\mathrm{pH}$ range by transforming into disordered conformation," Journal of Biological Chemistry, vol. 280, no. 29, pp. 27029-27034, 2005.

[14] R. Kern, A. Malki, J. Abdallah, J. Tagourti, and G. Richarme, "Escherichia coli HdeB is an acid stress chaperone," Journal of Bacteriology, vol. 189, no. 2, pp. 603-610, 2007.

[15] T. Schneiders, T. M. Barbosa, L. M. McMurry, and S. B. Levy, "The Escherichia coli transcriptional regulator MarA directly represses transcription of purA and hdeA," Journal of Biological Chemistry, vol. 279, no. 10, pp. 9037-9042, 2004.

[16] M. Shin, M. Song, H. R. Joon et al., "DNA looping-mediated repression by histone-like protein $\mathrm{H}-\mathrm{NS}$ : specific requirement of $\mathrm{E} \sigma^{70}$ as a cofactor for looping," Genes and Development, vol. 19, no. 19, pp. 2388-2398, 2005.

[17] D. L. Tucker, N. Tucker, and T. Conway, "Gene expression profiling of the $\mathrm{pH}$ response in Escherichia coli," Journal of Bacteriology, vol. 184, no. 23, pp. 6551-6558, 2002.

[18] J. Itou, Y. Eguchi, and R. Utsumi, "Molecular mechanism of transcriptional cascade initiated by the EvgS/EvgA system in Escherichia coli K-12," Bioscience, Biotechnology and Biochemistry, vol. 73, no. 4, pp. 870-878, 2009.

[19] M. L. Urbanowski, L. T. Stauffer, and G. V. Stauffer, "The $g_{c} v B$ gene encodes a small untranslated RNA involved in expression of the dipeptide and oligopeptide transport systems in Escherichia coli," Molecular Microbiology, vol. 37, no. 4, pp. 856-868, 2000.

[20] C. M. Sharma, F. Darfeuille, T. H. Plantinga, and J. Vogel, "A small RNA regulates multiple ABC transporter mRNAs by targeting C/A-rich elements inside and upstream of ribosomebinding sites," Genes and Development, vol. 21, no. 21, pp. 2804-2817, 2007.

[21] S. C. Pulvermacher, L. T. Stauffer, and G. V. Stauffer, "The role of the small regulatory RNA GcvB in GcvB/mRNA 
posttranscriptional regulation of $o p p A$ and $d p p A$ in Escherichia coli," FEMS Microbiology Letters, vol. 281, no. 1, pp. 42-50, 2008.

[22] S. C. Pulvermacher, L. T. Stauffer, and G. V. Stauffer, "Role of the sRNA GcvB in regulation of cycA in Escherichia coli," Microbiology, vol. 155, no. 1, pp. 106-114, 2009.

[23] S. C. Pulvermacher, L. T. Stauffer, and G. V. Stauffer, "The small RNA GcvB regulates sst $T$ mRNA expression in Escherichia coli," Journal of Bacteriology, vol. 91, no. 1, pp. 238248, 2009.

[24] C. M. Sharma, K. Papenfort, S. R. Pernitzsch, H. J. Mollenkopf, J. C. D. Hinton, and J. Vogel, "Pervasive post-transcriptional control of genes involved in amino acid metabolism by the Hfq-dependent GcvB small RNA," Molecular Microbiology, vol. 81, no. 5, pp. 1144-1165, 2011.

[25] Y. Jin, R. M. Watt, A. Danchin, and J. D. Huang, "Small noncoding RNA GcvB is a novel regulator of acid resistance in Escherichia coli," BMC Genomics, vol. 10, article 165, 2009.

[26] S. C. Pulvermacher, L. T. Stauffer, and G. V. Stauffer, "Role of the Escherichia coli $\mathrm{Hfq}$ protein in $\mathrm{GcvB}$ regulation of $o p p A$ and $d p p A$ mRNAs," Microbiology, vol. 155, no. 1, pp. 115-123, 2009.

[27] R. L. Wilson, P. S. Steiert, and G. V. Stauffer, "Positive regulation of the Escherichia coli glycine cleavage enzyme system," Journal of Bacteriology, vol. 175, no. 3, pp. 902-904, 1993.

[28] R. L. Wilson and G. V. Stauffer, "DNA sequence and characterization of GcvA, a LysR family regulatory protein for the Escherichia coli glycine cleavage enzyme system," Journal of Bacteriology, vol. 176, no. 10, pp. 2862-2868, 1994.

[29] A. D. Jourdan and G. V. Stauffer, "Genetic analysis of the GcvA binding site in the gcvA control region," Microbiology, vol. 145, no. 8, pp. 2153-2162, 1999.

[30] S. M. Panasenko, J. R. Cameron, R. W. Davis, and I. R. Lehman, "Five hundredfold overproduction of DNA ligase after induction of a hybrid lambda lysogen constructed in vitro," Science, vol. 196, no. 4286, pp. 188-189, 1977.

[31] A. Arnqvist, A. Olsen, and S. Normark, " $\sigma^{s}$-dependent growth-phase induction of the $\operatorname{csg} B A$ promoter in Escherichia coli can be achieved in vivo by $\sigma^{70}$ in the absence of the nucleoid-associated protein H-NS," Molecular Microbiology, vol. 13, no. 6, pp. 1021-1032, 1994.

[32] F. Hommais, E. Krin, J. Y. Coppée et al., "GadE (YhiE): a novel activator involved in the response to acid environment in Escherichia coli," Microbiology, vol. 150, no. 1, pp. 61-72, 2004.

[33] A. Tramonti, M. De Canio, and D. De Biase, "GadX/GadWdependent regulation of the Escherichia coli acid fitness island: transcriptional control at the gadY-gadW divergent promoters and identification of four novel 42 bp GadX/GadW-specific binding sites," Molecular Microbiology, vol. 70, no. 4, pp. 965982, 2008.

[34] C. Ruiz, L. M. McMurry, and S. B. Levy, "Role of the multidrug resistance regulator MarA in global regulation of the hdeAB acid resistance operon in Escherichia coli," Journal of Bacteriology, vol. 190, no. 4, pp. 1290-1297, 2008.

[35] R. L. Wilson, M. L. Urbanowski, and G. V. Stauffer, "DNA binding sites of the LysR-type regulator GcvA in the $g_{c} v$ and $g c v A$ control regions of Escherichia coli," Journal of Bacteriology, vol. 177, no. 17, pp. 4940-4946, 1995.

[36] L. M. Guzman, D. Belin, M. J. Carson, and J. Beckwith, "Tight regulation, modulation, and high-level expression by vectors containing the arabinose $\mathrm{P}(\mathrm{BAD})$ promoter," Journal of Bacteriology, vol. 177, no. 14, pp. 4121-4130, 1995.
[37] M. J. Casadaban, J. Chou, and S. N. Cohen, "In vitro gene fusions that join an enzymatically active $\beta$-galactosidase segment to amino-terminal fragments of exogenous proteins: Escherichia coli plasmid vectors for the detection and cloning of translational initiation signals," Journal of Bacteriology, vol. 143, no. 2, pp. 971-980, 1980.

[38] M. L. Urbanowski and G. V. Stauffer, "Autoregulation by tandem promoters of the Salmonella typhimurium LT2 metJ gene," Journal of Bacteriology, vol. 165, no. 3, pp. 740-745, 1986.

[39] K. Shimada, R. A. Weisberg, and M. E. Gottesman, "Prophage lambda at unusual chromosomal locations. I. Location of the secondary attachment sites and the properties of the lysogens," Journal of Molecular Biology, vol. 63, no. 3, pp. 483-503, 1972.

[40] A. C. Y. Chang and S. N. Cohen, "Construction and characterization of amplifiable multicopy DNA cloning vehicles derived from the P15A cryptic miniplasmid," Journal of Bacteriology, vol. 134, no. 3, pp. 1141-1156, 1978.

[41] J. Miller, Experiments in Molecular Genetics, Cold Spring Harbor Laboratory Press, Cold Spring Harbor, NY, USA, 1972.

[42] H. J. Vogel and D. M. Bonner, "Acetylornithinase of Escherichia coli: partial purification and some properties," The Journal of Biological Chemistry, vol. 218, no. 1, pp. 97-106, 1956.

[43] J. Gorden and P. L. C. Small, "Acid resistance in enteric bacteria," Infection and Immunity, vol. 61, no. 1, pp. 364-367, 1993.

[44] M. P. Castanie-Cornet and J. W. Foster, "Escherichia coli acid resistance: CAMP receptor protein and a 20 bp cisacting sequence control $\mathrm{pH}$ and stationary phase expression of the $\operatorname{gadA}$ and $\operatorname{gadBC}$ glutamate decarboxylase genes," Microbiology, vol. 147, no. 3, pp. 709-715, 2001.

[45] M. P. Castanié-Cornet, H. Treffandier, A. Francez-Charlot, C. Gutierrez, and K. Cam, "The glutamate-dependent acid resistance system in Escherichia coli: essential and dual role of the His-Asp phosphorelay RcsCDB/AF," Microbiology, vol. 153, no. 1, pp. 238-246, 2007.

[46] J. A. Opdyke, J. G. Kang, and G. Storz, "GadY, a small-RNA regulator of acid response genes in Escherichia coli," Journal of Bacteriology, vol. 186, no. 20, pp. 6698-6705, 2004.

[47] R. A. Lease, D. Smith, K. McDonough, and M. Belfort, "The small noncoding DsrA RNA is an acid resistance regulator in Escherichia coli," Journal of Bacteriology, vol. 186, no. 18, pp. 6179-6185, 2004.

[48] L. D. Wonderling, M. L. Urbanowski, and G. V. Stauffer, "GcvA binding site 1 in the $g c v T H P$ promoter of Escherichia coli is required for GcvA-mediated repression but not for GcvAmediated activation," Microbiology, vol. 146, no. 11, pp. 29092918, 2000.

[49] A. Zhang, K. M. Wassarman, C. Rosenow, B. C. Tjaden, G. Storz, and S. Gottesman, "Global analysis of small RNA and mRNA targets of Hfq," Molecular Microbiology, vol. 50, no. 4, pp. 1111-1124, 2003.

[50] I. D. Hiles, M. P. Gallagher, D. J. Jamieson, and C. F. Higgins, "Molecular characterization of the oligopeptide permease of Salmonella typhimurium," Journal of Molecular Biology, vol. 195, no. 1, pp. 125-142, 1987.

[51] M. W. Smith and J. W. Payne, "Simultaneous exploitation of different peptide permeases by combinations of synthetic peptide smugglins can lead to enhanced antibacterial activity," FEMS Microbiology Letters, vol. 58, no. 3, pp. 311-316, 1990. 

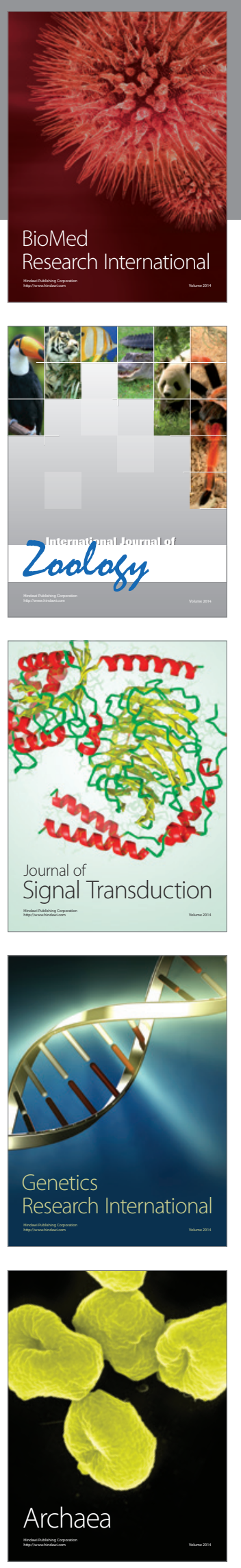
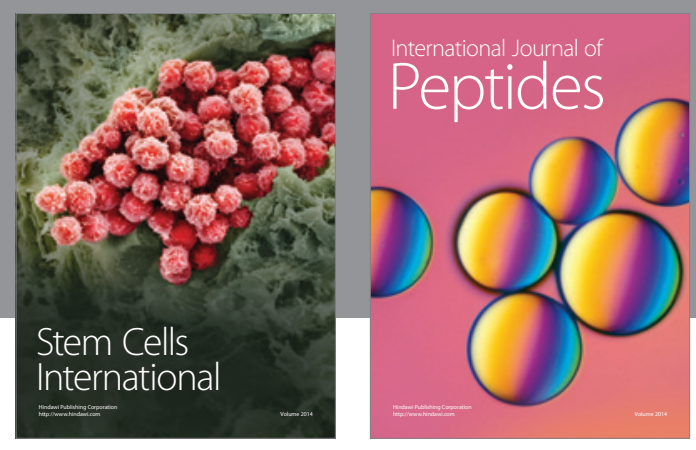

Submit your manuscripts at

http://www.hindawi.com
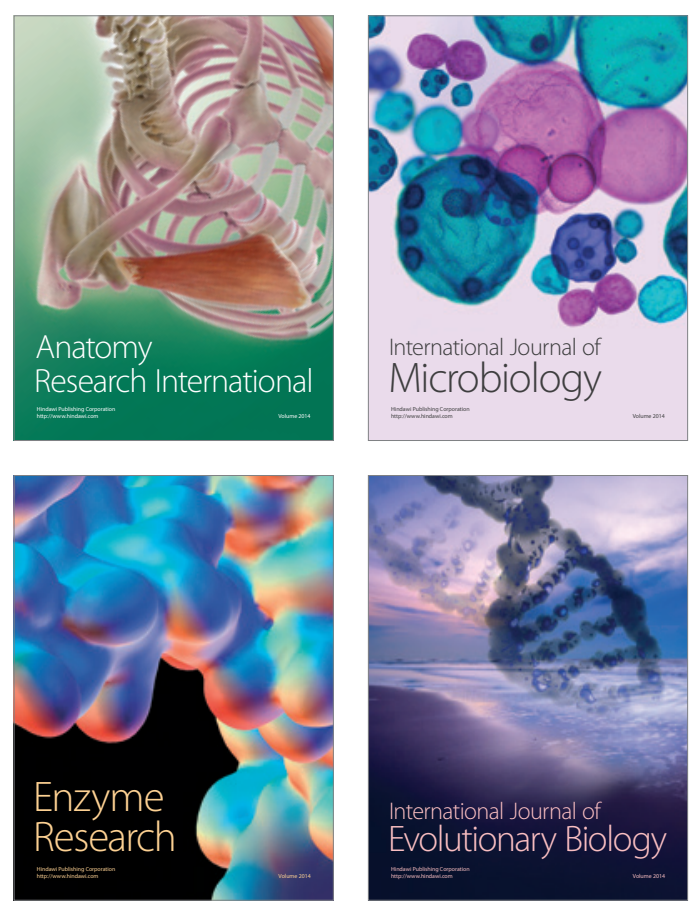
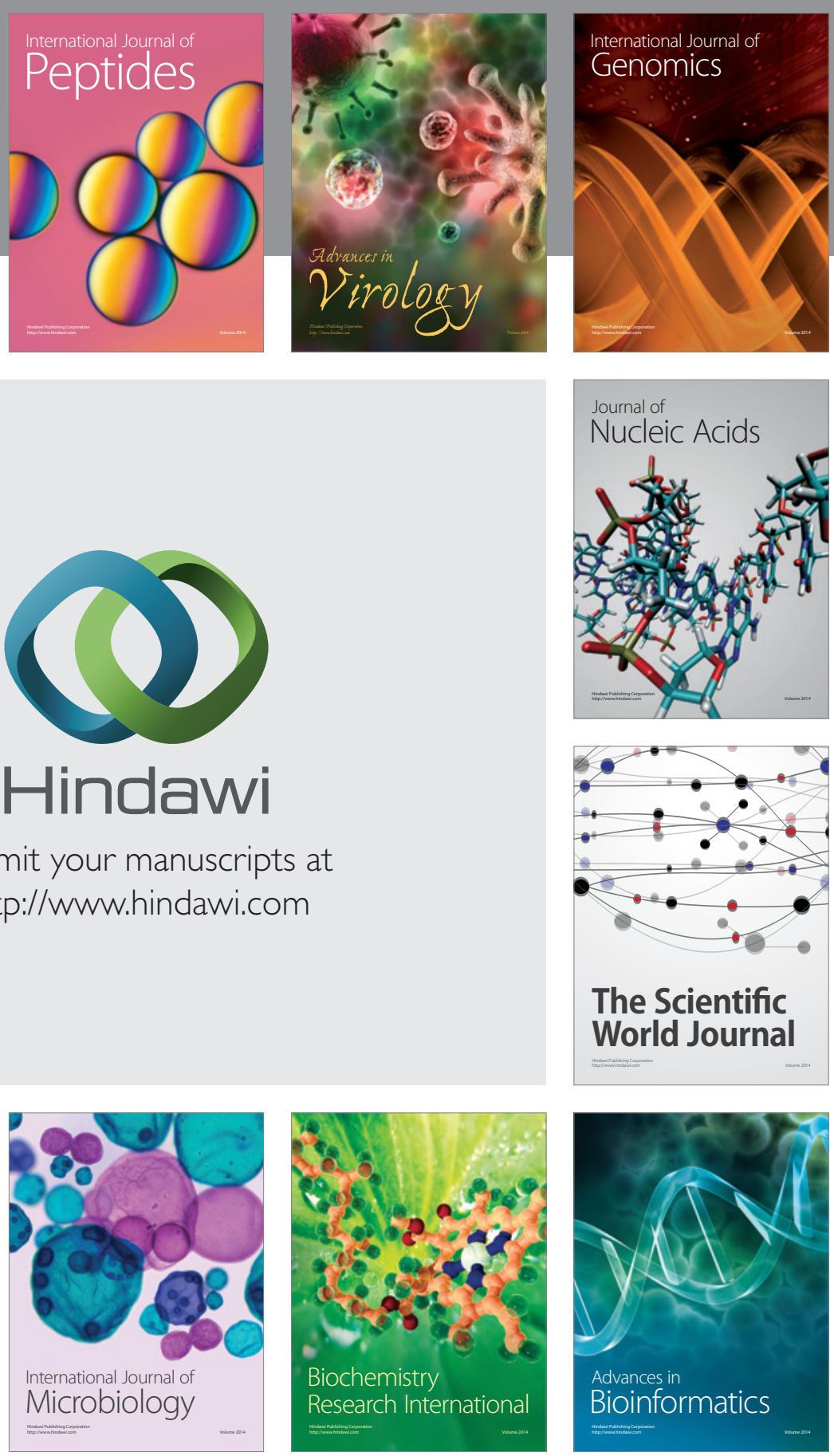

The Scientific World Journal
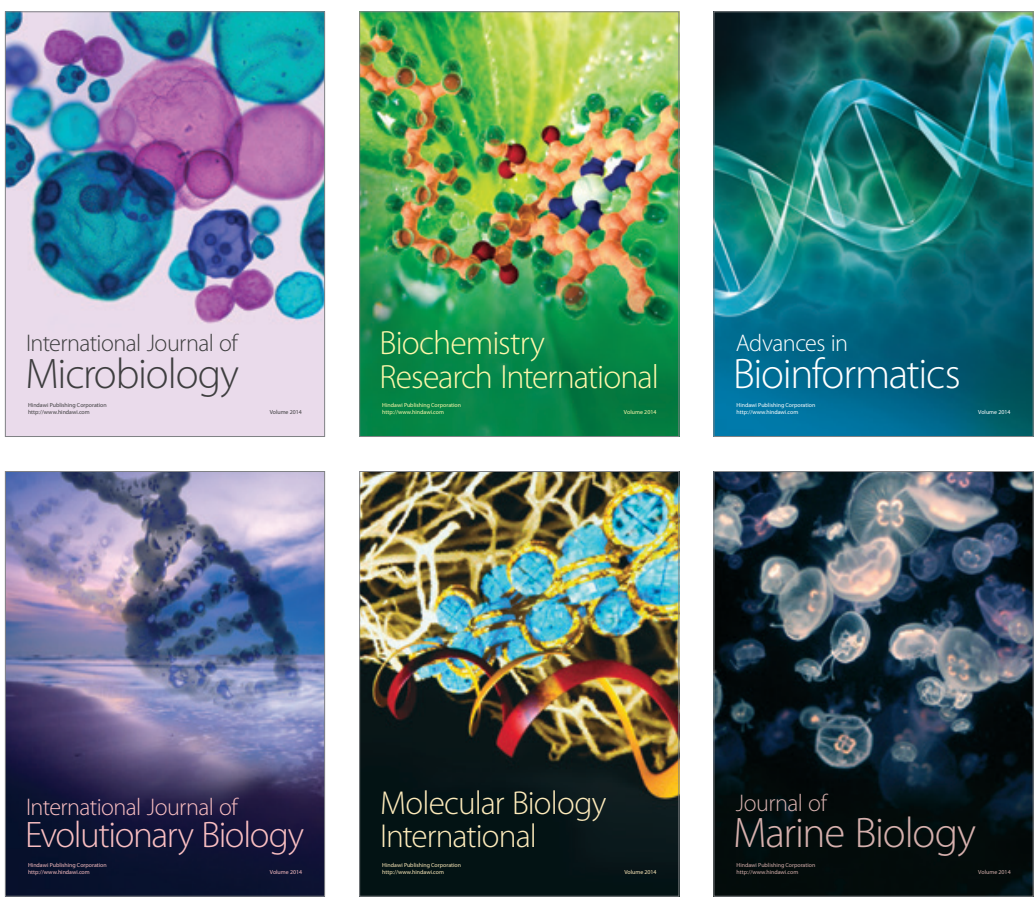